
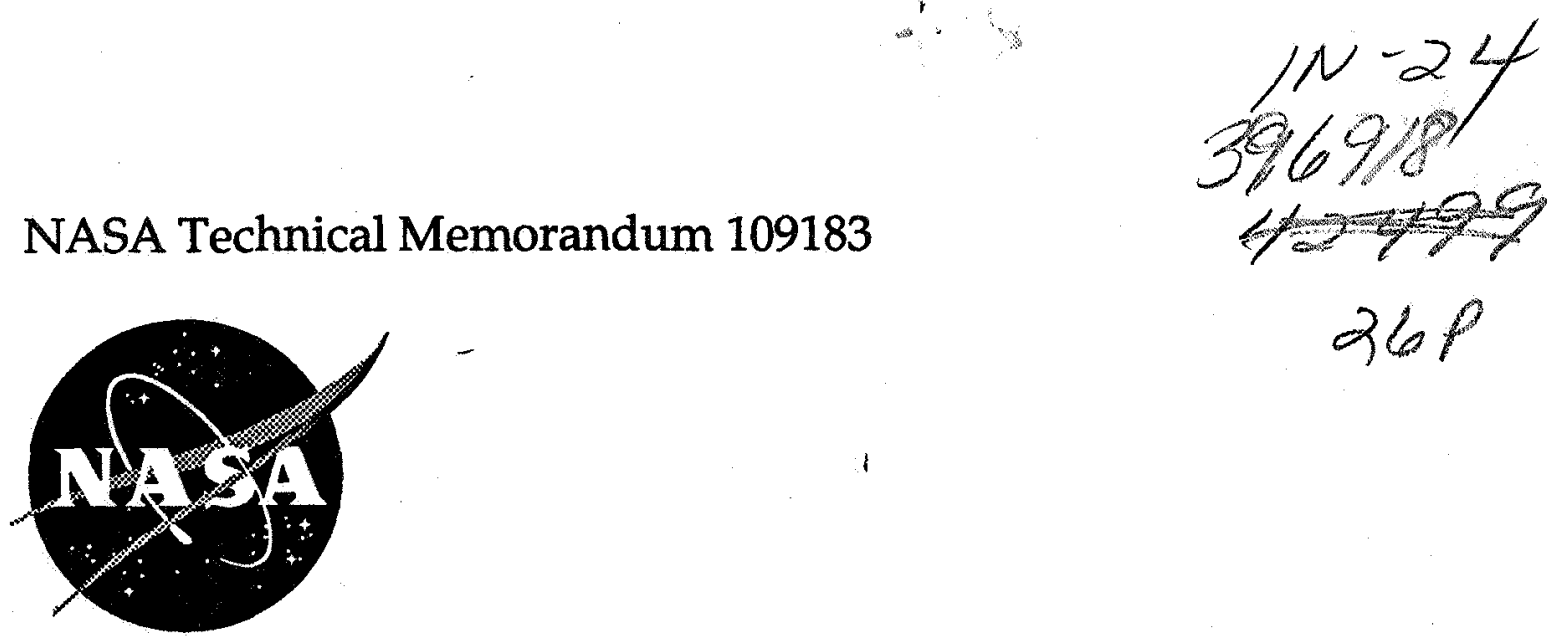

\title{
Three-Dimensional CTOA and Constraint Effects During Stable Tearing in a Thin-Sheet Material
}

D. S. Dawicke

Analytical Services and Materials, Inc., Hampton, Virginia

J. C. Newman, Jr.

Langley Research Center, Hampton, Virginia

C. A. Bigelow

FAA Technical Center, Atlantic City, New Jersey

February 1995

(NASA-TM-109183) THREE-DIMENSIONAL

N95-22928 CTOA AND CONSTRAINT EFFECTS DURING

STABLE TEARING IN A THIN-SHEET

MATERIAL (NASA. Langley Research Unclas Center) $26 \mathrm{p}$

National Aeronautics anu

Space Administration

Langley Research Center

Hampton, Virginia 23681-0001 


\title{
THREE-DIMENSIONAL CTOA AND CONSTRAINT EFFECTS DURING STABLE TEARING IN A THIN-SHEET MATERIAL
}

\author{
D.S. Dawicke1 , J.C. Newman, Jr. ${ }^{2}$, and C.A. Bigelow ${ }^{3}$
}

\section{ABSTRACT}

A small strain theory, three-dimensional elastic-plastic finite element analysis was used to simulate fracture in thin sheet 2024-T3 aluminum alloy in the T-L orientation. Both straight and tunneled cracks were modeled. The tunneled crack front shapes as a function of applied stress were obtained from the fracture surface of tested specimens. The stable crack growth behavior was measured at the specimen surface as a function of applied stress. The fracture simulation modeled the crack tunneling and extension as a function of applied stress. The results indicated that the global constraint factor, $\alpha_{\mathrm{g}}$, initially dropped during stable crack growth. After peak applied stress was achieved, $\alpha_{\mathrm{g}}$ began to increase slightly. The effect of crack front shape on $\alpha_{\mathrm{g}}$ was small, but the crack front shape did greatly influence the local constraint and through-thickness crack-tip opening angle (CTOA) behavior. The surface values of CTOA for the tunneled crack front model agreed well with experimental measurements, showing the same initial decrease from high values during the initial $3 \mathrm{~mm}$ of crack growth at the specimen's surface. At the same time, the interior CTOA values increased from low angles. After the initial stable tearing region, the CTOA was constant through the thickness. The three-dimensional analysis appears to confirm the potential of CTOA as a two-dimensional fracture criterion.

\section{NOMENCLATURE}

b Uncracked ligament length, $\mathrm{mm}$

B Sheet thickness, $\mathrm{mm}$

$\checkmark$ Poisson's ratio

E Elastic modulus, $\mathrm{MPa}$

${ }^{1}$ Senior Scientist, Analytical Services and Materials, Inc., Hampton, VA 23666

2 Senior Scientist, NASA Langley Research Center, Hampton, VA 23665

${ }^{3}$ Senior Scientist, FAA Technical Center, Atlantic City, NJ 08405 
a Half crack length, $\mathrm{mm}$

S Applied stress, MPa

$\Delta \mathrm{a}_{\mathrm{s}} \quad$ Crack growth at the specimen's surface, $\mathrm{mm}$

$\mathrm{x}, \mathrm{y}, \mathbf{z}$, Cartesian coordinates, $\mathrm{mm}$

$\mathrm{u}, \mathrm{v}, \mathrm{w}$ Displacements in the $\mathrm{x}, \mathrm{y}$, and $\mathrm{z}$ directions, $\mathrm{mm}$

$\sigma_{\mathrm{ii}} \quad$ Normal stress in the $\mathrm{i}$ direction, $\mathrm{MPa}$

$\sigma_{0} \quad$ Flow stress (average of yield and ultimate), $\mathrm{MPa}$

$\alpha_{\mathrm{g}} \quad$ Global constraint factor

$\mathrm{A}_{\mathrm{i}} \quad$ Projected area of element $\mathrm{i}$ on the crack plane, $\mathrm{mm}^{2}$

$A_{m} \quad$ Total projected area of all yielded elements on the crack plane, $\mathrm{mm}^{2}$

K Stress-intensity factor, MPa $\sqrt{m}$

$\mathrm{K}_{\mathbf{n}} \quad$ Normalized stress-intensity factor, MPa $\sqrt{\mathrm{m}}$

$\psi_{\mathrm{c}} \quad$ Critical crack-tip opening angle, degree

$v_{i} \quad v$-displacement at location of $\psi_{c}$ measurement, $\mathrm{mm}$

$\mathrm{x}_{\mathrm{i}} \quad$ Distance from crack-tip to location of $\psi_{\mathrm{c}}$ measurement, $\mathrm{mm}$

w Half width of specimen, $\mathrm{mm}$

\section{INTRODUCTION}

The prediction of residual strength in an aircraft fuselage structure requires a fracture criterion that can account for large amounts of stable tearing in thin-sheet material. One criterion that has been proposed is the crack-tip opening angle (CTOA) [16]. This criterion states that stable crack growth will occur when the local angle made by the upper crack surface, crack-tip, and lower crack surface reaches a critical value. Experimental studies have shown that at the surface, initial CTOA values are high, but quickly decrease and maintain a constant value after a small amount of stable crack growth [7-9]. Reuter and Lloyd [10] have shown experimentally that for a surface crack, CTOA is not constant around the crack perimeter. Two-dimensional numerical studies that neglect the initial transient and through-thickness variation in CTOA behavior have shown that this criterion can successfully be used to predict residual strength for a number of different specimen configurations [8, 11-13].

The early stage of stable tearing where the measured surface CTOA is not constant has prompted concerns about the local crack-tip stress fields and the constraint in thin sheet materials. Hom and McMeeking [14] analyzed stationary, straight, through- 
thickness notches in thin sheets using a large deformation theory, three-dimensional elastic-plastic finite element analysis. Newman et al $[8,15-16]$ analyzed stationary, straight and tunneled cracks, using a small strain theory, three-dimensional elastic-plastic finite element analysis. Both found that considerable constraint develops even in thin materials where significantly higher stresses develop in the interior than on the surface.

In addition to constraint variations and the large CTOA values during early stages of crack growth, significant changes in crack front shape also occur. Sutton, Dawicke, and Newman [17] have shown that for 2024-T3 aluminum alloy in the T-L orientation (load applied perpendicular to the rolling direction with the crack parallel to the rolling direction), stable crack growth will initiate in the interior. The crack will continue to grow stably at a higher rate in the interior than at the surface until the crack length has grown about $3 \mathrm{~mm}$ at the surface. By this time, the crack front has developed a deeply tunneled shape that extends in a self-similar manner [17]. Shear lips did not form in this orientation.

Thus, the initial stage of fracture in thin sheet aluminum appears to be dominated by variations in constraint, crack front shape, and CTOA. Furthermore, even in the steady state region, where the surface measurements of CTOA are constant, the crack front shape can be severely tunneled. These issues raise concerns over the validity of using surface measurements of CTOA as a fracture criterion in a two-dimensional analysis.

The objective of this paper is to numerically examine the initial transient stage of fracture in thin-sheet materials as well as the effect of crack tunneling on the steady state region. A three-dimensional, elastic-plastic finite-element simulation of stable crack growth in thin sheet 2024-T3 aluminum alloy in the T-L orientation will be presented. The analyses considered both straight and tunneled crack fronts. Experimental data used in the numerical simulations were taken from Ref. 17. Comparisons are made between the critical crack-tip opening angle (CTOA), global constraint factor, and throughthickness stresses for the tunneled and straight crack fronts. 


\section{CRACK CONFIGURATION AND MATERIAL PROPERTIES}

A middle crack tension, $\mathrm{M}(\mathrm{T})$, specimen $76.2 \mathrm{~mm}$ wide by $2.3 \mathrm{~mm}$ thick (initial $\mathrm{a} / \mathrm{w}=0.33$ and $\mathrm{a} / \mathrm{B}=5.56$ ) was analyzed. The material was $2024-\mathrm{T} 3$ aluminum alloy in the $\mathrm{T}-\mathrm{L}$ orientation. The modulus of elasticity (E) was $71,400 \mathrm{MPa}$ and Poisson's ratio (v) was 0.3 . In the analyses, a multi-linear representation of the uniaxial stress-strain curve, given in Table 1, was used. The stable tearing behavior was obtained from fracture tests where the applied stress $(S)$ was recorded as a function of crack growth at the specimen surface $\left(\Delta a_{s}\right)$ [17], as shown in Figure 1. An average of the applied stress against crack extension at the specimen surface data is given in Table 2.

Deeply tunneled crack fronts were observed to develop during stable tearing tests of $M(T)$ specimens [17]. The tunneled crack front shapes were obtained from fracture tests where the specimens were allowed to stably tear for a predetermined amount of crack growth at the specimen surface. Then, the specimens were fatigue cycled at a high stress ratio until failure. These changes in loading produced both macroscopic and microscopic changes in the fracture surface, creating a distinct boundary between the stable tearing and fatigue crack growth regions. Each boundary represents the crack front shape at a specific time during the stable tearing process.

The shape of the crack front changed significantly during the early stages of stable tearing, as shown in Figure 2. Prior to stable tearing, the crack front shape was slightly tunneled due to the fatigue cycling used to generate a sharp crack-tip. During the initial stages of stable tearing, the crack grew faster in the interior. By the time the crack growth at the specimen surface reached $0.25 \mathrm{~mm}$, the growth in the interior was about $1 \mathrm{~mm}$. The crack front shape stabilized after about $3 \mathrm{~mm}$ of crack growth at the specimen surface. The stabilized shape was deeply tunneled, also shown in Figure 2. Also, it was observed that the fracture surfaces were macroscopically perpendicular to the direction of loading (i.e., shear lips did not form) [17].

The crack front shapes given in Figure 2 were digitized and fit with polynomial expressions to describe the crack front shape as a function of through-thickness position. Additional crack front profiles were generated from the polynomial curve fits to describe the approximate crack front shape at each $0.25 \mathrm{~mm}$ increment of crack growth at the specimen surface, as shown in Figure 3. 


\section{FINITE ELEMENT ANALYSES}

A three-dimensional, elastic-plastic finite element analysis code, ZIP3D [18] was used for the fracture simulation. The program uses 8-noded, hexahedral elements, the von Mises yield criterion, isotropic hardening, small-strain deformation theory, and Drucker's associated flow rule. The elastic-plastic analysis is based on the initial-stress method and the incremental theory of plasticity [18]. The finite-element formulation and solution method are given in Ref. 19.

Two different finite element models were created; one with straight, and one with tunneled crack front shapes. Symmetry conditions required that only one eighth of the $\mathrm{M}(\mathrm{T})$ specimens be modeled. Both models used five layers of elements through the half thickness $(B / 2=1.143 \mathrm{~mm})$ and had 7398 nodes and 5650 elements. The thicknesses of the layers 1 through 5 (with the layer adjacent to the mid-plane denoted as layer 1) were $0.125,0.125,0.125,0.075$, and 0.05 of $B$, respectively. The crack plane elements of the straight crack front mesh were $0.25 \mathrm{~mm}$ in the $y$-direction and the $\mathrm{x}$-direction, as shown in Figure 4. The crack plane elements of the tunneled crack front mesh were $0.25 \mathrm{~mm}$ in the $y$-direction and in the $x$-direction at the surface, but the length of the $x$-direction elements in the interior were greater to reflect the extent of tunneling present. This is illustrated in Figure 3, where a view of the crack plane $(x-z$ plane at $y=0)$ is shown.

Normally, the nodes along the crack line and ahead of the crack-tip are fixed, while those behind are free. This analysis uses springs along the crack line to change boundary conditions associated with crack growth. The spring stiffness is set equal to zero for nodes behind the crack tip and assigned an extremely large value for nodes ahead of the crack tip. A nodal-release procedure [20] is employed for crack growth. Stable crack growth was simulated by allowing the crack to grow when the applied stress reached a predetermined level. These predetermined stress levels were obtained from the fracture test results reported in Ref. 17 and shown in Figure 1. In these tests, the crack length at the surface and the applied stress were measured during stable tearing. The curve fit shown in Figure 1 was evaluated to give the stress required for crack growth (critical stress) for each of the discrete crack lengths (measured at the surface) used in the finite element model. These values are listed in Table 2. In the finite element simulation, the entire crack front was allowed to advance one node when the applied stress reached the critical value corresponding to the current crack length at the surface. 


\section{RESULTS AND DISCUSSION}

Elastic-plastic finite element analyses were conducted to simulate fracture in the $\mathrm{M}(\mathrm{T})$ specimens. Two models were examined; in the first, a straight through-thickness crack front was modeled and in the second, a tunneled through-thickness crack front was modeled. Loading was simulated with uniform tractions in the y-axes along the $y=76.2 \mathrm{~mm}$ surface of the models. The material stress-strain curve, applied stress-crack growth behavior at the specimen surface, and crack front profile shapes were obtained from experimental measurements [17]. The finite element analyses used this information to define the fracture behavior and generate the local crack-tip stresses, the global constraint factor, local crack-opening displacements, and through-thickness crack-tip opening angle (CTOA) values.

\section{Local Crack-Tip Stresses}

The stresses ahead of the crack tip in the direction of loading $\left(\sigma_{\mathrm{yy}}\right)$ were obtained from the finite element analyses of the straight and tunneled crack fronts. The reported $\sigma_{\mathrm{yy}}$ stresses are at the applied stress level required for crack growth, but before the crack front was allowed to grow. Due to the singularity at the crack tip and the approximations inherent in the small strain finite element analysis, the stresses in the crack-tip element were ignored. However, the stresses in the other elements should be reasonably accurate.

The $\sigma_{\mathrm{yy}}$ stresses, normalized by the flow stress $\left(\sigma_{0}\right)$, on the crack plane ahead of the crack-tip in the straight crack front analysis are shown in Figures 5a and $5 \mathrm{~b}$ for the surface and mid-plane elements, respectively. Prior to crack growth, the trends of the $\sigma_{\mathrm{yy}}$ stresses agree with the large deformation theory finite element results of Hom and McMeeking [14]. Their analysis found that, for a blunt notch in a thin sheet, the $\sigma_{y y}$ stresses at the mid-plane were greater than those at the surface with normalized peak stresses $\left(\sigma_{y y} / \sigma_{0}\right)$ of about 1.2 at the surface and 2.0 at the mid-plane. The present results exhibited similar behavior with normalized peak stresses of 1.3 at the surface and 2.0 at the mid-plane.

The $\sigma_{\text {yy }}$ stresses, normalized by the flow stress $\left(\sigma_{0}\right)$, on the crack plane ahead of the crack tip in the tunneled crack front analysis are shown in Figures $6 \mathrm{a}$ and $6 \mathrm{~b}$ for the surface and mid-plane elements, respectively. For the tunneled crack front, the trends of the normalized $\sigma_{\mathrm{yy}}$ stresses at the mid-plane as a function of distance from the crack tip 
agree with the straight crack results for the mid-plane. However, the surface results are different for the two crack front shapes. After crack growth, the normalized stresses ahead of the crack-tip in the tunneled crack front model decrease from a value around 2, reach a minimum of about 1 and increase to a second peak before decreasing once again.

The differences in the normalized $\sigma_{\mathrm{yy}}$ stresses along the crack plane in the tunneled and straight crack front finite element analyses are further illustrated in the contour plots of Figure 7. These plots show lines of constant $\sigma_{\mathrm{yy}} / \sigma_{0}$ stress in the steadystate region of crack growth (just prior to the 10th increment of crack growth) for an area extending from the crack front to about $3 \mathrm{~mm}$ ahead of the crack front. Also superimposed on these plots are the finite element sizes along the crack plane. The high $\sigma_{\mathrm{yy}} / \sigma_{0}$ stress gradients occur over a minimum of 5 elements, which, though not sufficient to capture the magnitude stresses at the crack front, should be sufficient to capture the behavioral trends and the stress magnitude several elements ahead of the crack front. The finite element results indicate that the wedge formed at the surface of the tunneled crack front significantly increases the near surface stresses. The stresses along the mid-plane of the tunneled crack front are also greater than those at a similar position in the straight crack front analysis.

\section{Global Constraint Factor}

The global constraint factor $\left(\alpha_{\mathrm{g}}\right)$ was defined by Newman, Bigelow, and Shivakumar [15] to be the average normal-stress-to-flow-stress ratio for elements in the plastic zone.

$$
\alpha_{g}=\frac{1}{A_{T}} \sum_{m=1}^{M}\left(\frac{\sigma_{y y}}{\sigma_{o}}\right)_{m} A_{m}
$$

where, $A_{m}$ is the projected area on the uncracked ligament of a yielded element $m, A_{T}$ is the total projected area for all elements that have yielded, and $M$ is the total number of yielded elements. Newman et al [16] found the global constraint factor to be nearly independent of specimen type for crack length to thickness $(\mathrm{a} / \mathrm{B})$ and uncracked ligament to thickness ratios (b/B) greater than 4. An equation expressing the global constraint as a function of the stress-intensity factor was obtained from elastic-plastic finite element analyses of stationary, straight through-thickness cracks in an elastic-perfectly plastic material [16] as 


$$
\begin{gathered}
\alpha_{\mathrm{g}}=1.15+1.25 \mathrm{e}^{-0.85 \mathrm{~K}_{\mathrm{n}}{ }^{1.5}} \\
\mathrm{~K}_{\mathrm{n}}=\frac{\mathrm{K}}{\sigma_{0} \sqrt{\mathrm{B}}} \\
\mathrm{K}=\mathrm{S} \sqrt{\pi \mathrm{a} \sec \left(\frac{\pi \mathrm{a}}{2 \mathrm{w}}\right)}
\end{gathered}
$$

Using Eqn. 1, the global constraint factor for the straight and tunneled crack analyses are plotted in Figure 8 as a function of the normalized stress-intensity factor. For the tunneled crack, the stress-intensity factor was calculated, using Eqn. 4, neglecting the crack front curvature and using the surface crack length measurement (Note: that by using the surface crack length, the average stress intensity factor of the tunneled crack would be about $10 \%$ less than that obtained using the crack length at maximum depth. This surface crack representation was used throughout the paper to be consistent with experimental measurements, where only the surface value is known.). Initially, $\alpha_{\mathrm{g}}$ for the tunneled crack is slightly greater than that of the straight crack for the same normalized stress-intensity factor. As the stress-intensity factor increases, $\alpha_{\mathrm{g}}$ levels off at 1.3 for both the crack front shapes. This value is higher than that calculated from Eqn. 2, however, the present analysis simulates a material that strain hardens rather than an elastic-perfectly plastic material. As the crack begins to grow, the global constraint factor drops until the maximum stress is reached. A slight increase in $\alpha_{\mathrm{g}}$ was observed after the peak stress was reached.

\section{Crack Surface Displacements and CTOA}

During the finite element simulation, the displacements of the nodes behind the crack tip on the crack plane were recorded at several stress levels and prior to each increment of crack growth. The displacements in the direction of loading (v) were used to calculate the crack-tip opening angle (CTOA). CTOA was calculated in the same manner as Dawicke and Sutton [9] using surface measurements. CTOA is defined to be the angle $\left(\psi_{\mathrm{c}}\right)$ made by a point on the upper crack surface, the crack tip, and a point on the lower crack surface directly below the one on the upper surface. The locations of the points on the upper and lower crack surfaces were $1 \mathrm{~mm}$ behind the crack-tip if the amount of stable tearing exceeded $1 \mathrm{~mm}$, or at the node ahead of the original crack front if the total amount of stable tearing was less than $1 \mathrm{~mm}$. This is illustrated in Figure 9 for displacements obtained from the finite element analysis. This definition was used to prevent anomalous CTOA values that would result from the blunted region formed at the original crack-tip. In terms of the finite element results, $\psi_{c}$ is determined from the $v$ - 
displacement at a distance $1 \mathrm{~mm}$ behind the crack-tip (or at the node immediately ahead of the original crack tip if $\Delta \mathrm{a}<1 \mathrm{~mm}$ ) and the $\mathrm{x}$-distance from the crack-tip to the point of $\mathrm{v}$ displacement measurement.

$$
\psi_{\mathrm{c}}=2 \tan ^{-1}\left(\frac{\mathrm{v}_{\mathrm{i}}}{\mathrm{x}_{\mathrm{i}}}\right)
$$

The CTOA was calculated just prior to each increment of crack growth (except the first) for both the tunneled crack front and the straight crack front models, as shown in Figures $10 \mathrm{a}$ and $10 \mathrm{~b}$, respectively. CTOA values were calculated at the surface $(\mathrm{z} / \mathrm{B}=0.5)$, the mid-plane $(\mathrm{z} / \mathrm{B}=0)$, and at different through-thickness locations $(\mathrm{z} / \mathrm{B}=0.125,0.25,0.375$, and 0.45$)$. The tunneled crack front simulation exhibited a considerable variation in CTOA through-the-thickness during the initial $3 \mathrm{~mm}$ of crack growth at the specimen's surface. The surface CTOA values agreed with the experimental surface measurements, with an initial angle of $10^{\circ}$ at a crack growth at the specimen's surface of $0.5 \mathrm{~mm}$. The calculated CTOA values decreased through-thethickness to a value of about $4^{\circ}$ at the mid-plane. After $3 \mathrm{~mm}$ of crack growth at the specimen's surface, all through-thickness calculations of CTOA approached the average CTOA $\left(4.7^{\circ}\right)$ that was experimentally measured at the surface [17]. The straight crack simulation showed very little variation in CTOA through-the-thickness. Initially, the calculated CTOA value was between $5^{\circ}$ and $6^{\circ}$ (with the lower value at the surface). As the simulation grew the crack, the calculated CTOA values decreased slightly to between $4^{\circ}$ and $5^{\circ}$.

To further illustrate the through-thickness variation in CTOA for the tunneled crack front, the crack opening displacement was plotted as a function of crack length and position through-the-thickness, as shown in Figures 11a and 11b for crack growth at the specimen surface of $0.75 \mathrm{~mm}$ and $4.75 \mathrm{~mm}$, respectively. The crack opening displacements shown in Figure 11 are just prior to the next increment of crack growth. In Figure 11a, the crack has grown three nodes past the original crack-tip. The large initial tunneling in the interior is evident, as is the severe blunting of the original crack front and the variation in CTOA through-the-thickness. The first two elements along the mid-plane are significantly larger (in the crack growth direction) than those at the surface due to the severe tunneling during the early stages of stable tearing. However, after the second increment of crack growth, the crack growth at the mid-plane becomes closer to that at the surface, yet the differences in CTOA remain large (see Figure 10a). In Figure 11b, 
the crack has reached a "steady-state" condition, where the crack front profile (imposed condition) and the CTOA (calculated result) are constant through-the-thickness.

A convergence study was not performed to assess the effect of element size on the through-the-thickness CTOA behavior. However, the element size used in this study was small enough to provide accurate predictions of stable tearing and local crack opening displacements in earlier two-dimensional predictions [8-9, 11-13]. The CTOA was determined four elements away from the crack front (except for the second and third increments of crack growth where two and three elements were used, respectively). Additional layers through-the-thickness and smaller elements would give more accurate results, but the trends shown in this analysis would probably not change.

The tunneled crack front finite element simulation indicates that CTOA may be a fracture criterion for thin-sheet materials that can be incorporated into a two-dimensional analysis. The three-dimensional analyses indicate that after steady-state conditions have been achieved, the CTOA measured at the surface is representative of what is happening in the interior. In the transient region the surface CTOA measurements are higher than in the interior and the average CTOA through-the-thickness is close to the steady-state CTOA. In a two-dimensional fracture simulation, using the constant steady-state CTOA during the transient region may be an adequate approximation, especially if the amount of stable tearing is large compared to the transient region. Earlier two-dimensional, elasticplastic finite element analyses, using the measured steady-state CTOA value as a fracture criterion, have successfully predicted fracture behavior of single and multiple cracks in $2.3 \mathrm{~mm}$ thick by $300 \mathrm{~mm}$ wide sheets of 2024-T3 [21].

\section{CONCLUSIONS}

A small strain theory, three-dimensional elastic-plastic finite element analysis was used to simulate fracture in thin sheet 2024-T3 aluminum alloy in the T-L orientation. Both straight and tunneled crack fronts were modeled. The tunneled crack front shapes were obtained from experimental measurements. The stable crack growth behavior was measured at the specimen surface as a function of applied stress. The fracture simulation modeled the crack tunneling and extension as a function of applied stress. The results indicate that: 
(1) The global constraint factor, $\alpha_{\mathrm{g}}$, dropped at the onset of stable crack growth. After peak stress was achieved, $\alpha_{\mathrm{g}}$ began to increase. The effect of crack front shape on $\alpha_{g}$ was small.

(2) The crack front shape did influence both the local constraint and through-thethickness CTOA behavior. Failure to account for these crack shapes in any threedimensional simulations or predictions may give inaccurate results.

(a) Local constraint differences: Prior to crack growth, the local $\sigma_{y y}$ stresses ahead of the crack-tip were higher at the mid-plane and lower at the surface in the tunneled crack model than they were in the straight crack model. In the straight crack model, both the surface and mid-plane $\sigma_{y y}$ stresses increased slightly with crack growth. In the tunneled crack model, the local stresses dropped during the initial crack growth. During the rest of the initial transient region $\left(\Delta \mathrm{a}_{\mathrm{s}}<3 \mathrm{~mm}\right)$, the mid-plane stresses increased sharply and the surface stress only slightly increased. After the initial transient region, the mid-plane stresses in the tunneled crack model were greater than and the surface stresses were less than those of the straight crack model.

(b) CTOA differences: Results from the tunneled crack front model indicated that during the initial transient region $\left(\Delta \mathrm{a}_{\mathrm{s}}<3 \mathrm{~mm}\right)$ the CTOA at the midplane was less than $4^{\circ}$ and increased with crack growth. The initial CTOA at the surface was about $10^{\circ}$ and decreased with crack growth, which agreed with experimental surface CTOA measurements. At other through-thickness locations, the CTOA values fell between the surface and mid-plane values. After the transient region, the experimentally measured through-the-thickness CTOA was nearly constant, at a value of $4.7^{\circ}$. For the straight crack front model, the CTOA was constant thought-the-thickness and the initial surface CTOA values did not agree with the experimental measurements.

(3) The three-dimensional analysis appears to confirm the potential of CTOA as a two-dimensional fracture criterion. In the initial transient region, the high angles measured at the surface do not reflect the behavior in the interior and an average value might be close to the steady state surface measurements. In the steady state crack growth region, the CTOA appears to be constant though-the-thickness. 


\section{REFERENCES}

[1] Wells, A. A., "Unstable Crack Propagation in Metals: Cleavage and Fast Fracture," in Proceedings of the Cranfield Crack Propagation Symposium, Vol. 1, 1961, pp. 210-230.

[2] Wells, A.A., "Application of Fracture Mechanics at and Beyond General Yielding," British Welding Journal, Vol. 11, 1961, pp. 563-570.

[3] Wells, A.A., "Notched Bar Tests, Fracture Mechanics and Brittle Strengths of Welded Structures," British Welding Journal, Vol. 12, 1963, pp. 2-13.

[4] Anderson, H., "Finite Element Representation of Stable Crack Growth," Journal of Mechanics and Physics of Solids, Vol. 21, 1973, pp. 337-356.

[5] de Koning, A. U., "A Contribution to the Analysis of Quasi Static Crack Growth in Steel Materials," in Fracture 1977, Proceedings of the 4th International Conference on Fracture, Vol. 3, pp. 25-31.

[6] Kanninen, M. F., "The Analysis of Stable Crack Growth in Type 304 Stainless Steel," in Proceedings of the International Conference of Fracture 1980, pp. 17591768.

[7] Demofonti, G. and Rizzi, L., "Experimental Evaluation of CTOA in Controlling Unstable Ductile Fracture Propagation," ESIS Pub. 9, 1991, pp. 693-703.

[8] Newman, J. C., Jr., Dawicke, D. S., and Bigelow, C. A., "Finite-Element Analysis and Measurement of CTOA During Stable Tearing in a Thin-Sheet Aluminum Alloy," Durability of Metal Aircraft Structures, S. N. Atluri, C. E. Harris, A. Hoggard, M. Miller, and S. G. Sampath, Eds., 1992, pp. 167-186.

[9] Dawicke, D. S. and Sutton, M. A., "Crack-Tip Opening Angle Measurements and Crack Tunneling Under Stable Tearing in Thin Sheet 2024-T3 Aluminum Alloy", NASA CR-191523, September 1993.

[10] Reuter, W. G. and Lloyd, W. R., "Measurements of CTOD and CTOA Around Surface-Crack Perimeters and Relationships Between Elastic and Elastic-Plastic CTOD Values," Surface-Crack Growth: Models, Experiments, and Structures, ASTM STP 1060, W. G. Reuter, J. H. Underwood, and J. C. Newman, Jr., Eds., American Society for Testing and Materials, Philadelphia, 1990, pp. 152-176.

[11] Newman, J. C., Jr., Dawicke, D. S., Sutton, M. A., and Bigelow, C. A., "A Fracture Criterion for Widespread Cracking in Thin-Sheet Aluminum Alloys," Durability and Structural Integrity of Airframes, Volume I, A. F. Blom, Ed., 1993, pp. 443-467.

[12] Dawicke, D. S., Sutton, M. A., Newman, J. C., Jr., and Bigelow, C. A., "Measurement and Analysis of Critical CTOA for an Aluminum Alloy Sheet," NASA TM-109024, 1993.

[13] Dawicke, D. S., Newman, J. C., Jr., Sutton, M. A., and Amstutz, B. E., "Stable Tearing Behavior of a Thin-Sheet Material with Multiple Cracks," NASA TM$109131,1994$. 
[14] Hom, C. L. and McMeeking, R. M., "Large Crack Tip Opening in Thin, ElasticPlastic Sheets," International Journal of Fracture, Vol. 45, 1990, pp. 103-122.

[15] Newman, J. C., Jr., Bigelow, C. A., and Shivakumar, K. N., "Three-Dimensional Elastic-Plastic Finite-Element Analyses of Constraint Variations in Cracked Bodies," Engineering Fracture Mechanics, Vol. 46, No. 1, 1993, pp. 1-13.

[16] Newman, J. C., Jr., Crews, J. H., Jr., Bigelow, C. A., and Dawicke, D. S., "Variations of a Global Constraint Factor in Cracked Bodies Under Tension and Bending Loads," Constraint Effects in Fracture: Theory and Applications, ASTM STP 1244, Mark Kirk and Ad Bakker, Eds., American Society of Testing and Materials, Philadelphia, 1994.

[17] Sutton, M. A., Dawicke, D. S., and Newman, J. C., Jr., "Orientation Effects on the Measurement and Analysis of Critical CTOA in an Aluminum Alloy Sheet," Fracture Mechanics: 26th Volume. ASTM STP 1256, Walter G. Reuter, John H. Underwood, and James C. Newman, Jr., Eds, American Society for Testing and Materials, Philadelphia, 1995.

[18] Shivakumar, K. N. and Newman, J. C., Jr., "ZIP3D - An Elastic and ElasticPlastic Finite-Element Analysis Program for Cracked Bodies," NASA TM $102753,1990$.

[19] Zienkiewicz, O. C., Valliappan, S., and King, I. P., "Elasto-Plastic Solutions of Engineering Problems, Initial Stress, Finite-Element Approach," International Journal of Numerical Methods in Engineering, Vol. 1, 1969, pp. 75-100.

[20] Chermahini, R. G., Shivakumar, K. N., and Newman, J. C., Jr., "ThreeDimensional Finite-Element Simulation of Fatigue Crack Growth and Closure," Mechanics of Fatigue Crack Closure, ASTM STP 982, J. C. Newman, Jr., and W. Elber, eds., 1988, pp. 398-413.

[21] Dawicke, D.S., Newman, J.C., Jr., Sutton, M.A., and Amstutz, B.E., "Influence of Crack History on the Stable Tearing Behavior of a Thin-Sheet Material with Multiple Cracks", FAA/NASA International Symposium on Advanced Structural Integrity Methods for Airframe Durability and Damage Tolerance, May 1994. 
Table 1

Multi-linear representation of the uniaxial stress-strain curve for 2024-T3 aluminum alloy in the T-L orientation [17]

\begin{tabular}{|c|l|}
\hline $\begin{array}{c}\sigma \\
(\mathrm{MPa})\end{array}$ & \multicolumn{1}{|c|}{$\varepsilon$} \\
\hline 303 & 0.00425 \\
\hline 355 & 0.015 \\
\hline 403 & 0.04 \\
\hline 448 & 0.1 \\
\hline 476 & 0.16 \\
\hline 476 & 0.2 \\
\hline
\end{tabular}

Table 2

Stable crack growth data for 2024-T3 aluminum alloy in the T-L orientation [17]

\begin{tabular}{|c|c|}
\hline $\begin{array}{c}\Delta \mathrm{a}_{\mathrm{s}} \\
(\mathrm{mm})\end{array}$ & $\begin{array}{c}\mathrm{S} \\
(\mathrm{MPa})\end{array}$ \\
\hline 0.00 & 193.0 \\
\hline 0.25 & 206.3 \\
\hline 0.50 & 212.0 \\
\hline 0.75 & 214.5 \\
\hline 1.00 & 216.0 \\
\hline 1.25 & 216.5 \\
\hline 1.50 & 216.3 \\
\hline 1.75 & 215.8 \\
\hline 2.00 & 215.2 \\
\hline 2.25 & 214.4 \\
\hline 2.50 & 213.7 \\
\hline 2.75 & 212.3 \\
\hline 3.00 & 211.0 \\
\hline 3.25 & 209.5 \\
\hline 3.50 & 208.2 \\
\hline 3.75 & 206.5 \\
\hline 4.00 & 203.6 \\
\hline 4.25 & 202.5 \\
\hline 4.50 & 201.2 \\
\hline 4.75 & 199.8 \\
\hline 10.0 & 165.0 \\
\hline & \\
\hline & \\
\hline
\end{tabular}




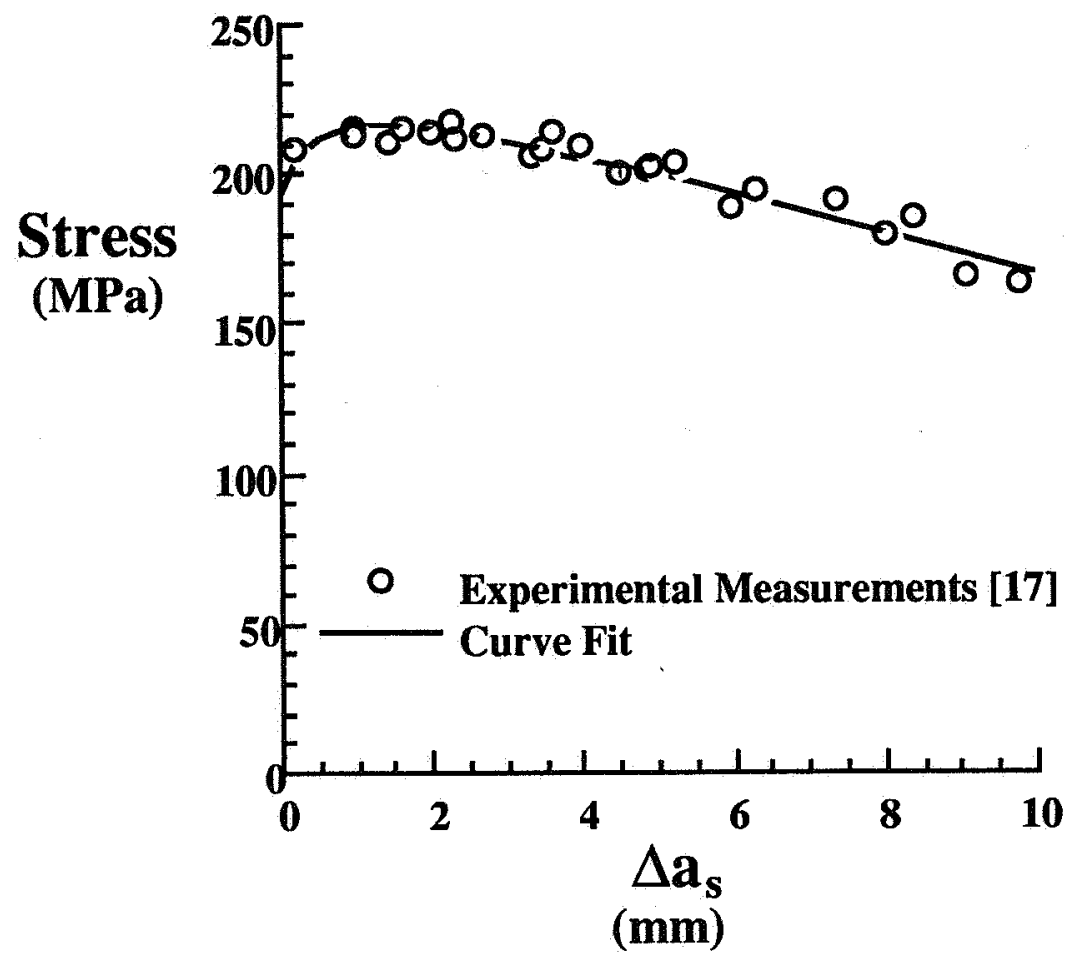

Figure 1 Experimental measurements of stress against crack growth at the surface and the multi-linear curve fit for 2024-T3 aluminum alloy in the T-L orientation 


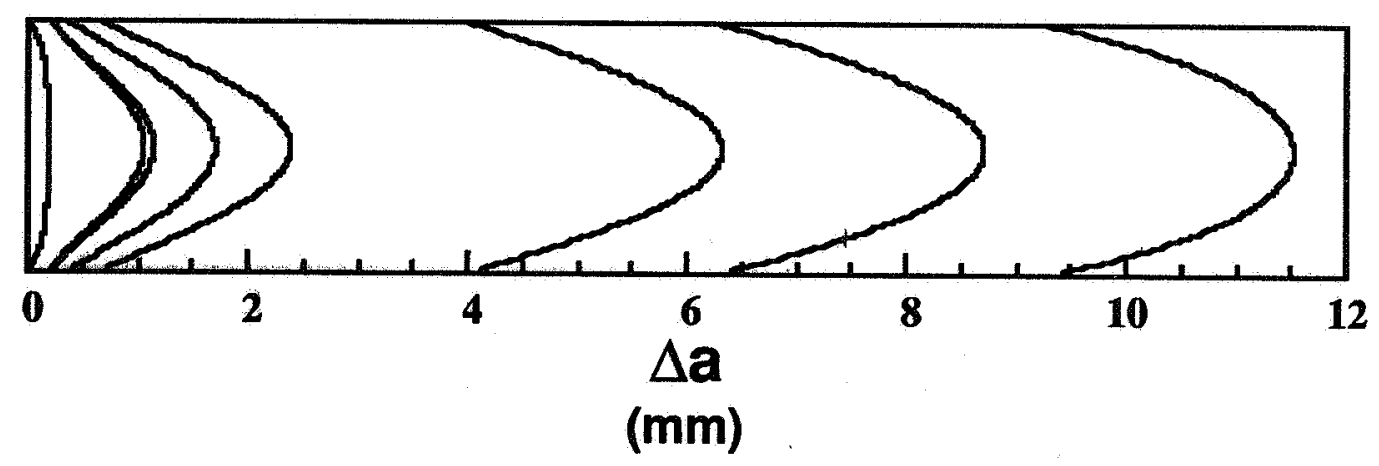

Figure 2 Crack front profiles during stable tearing for 2024-T3 in the T-L orientation [17]. 


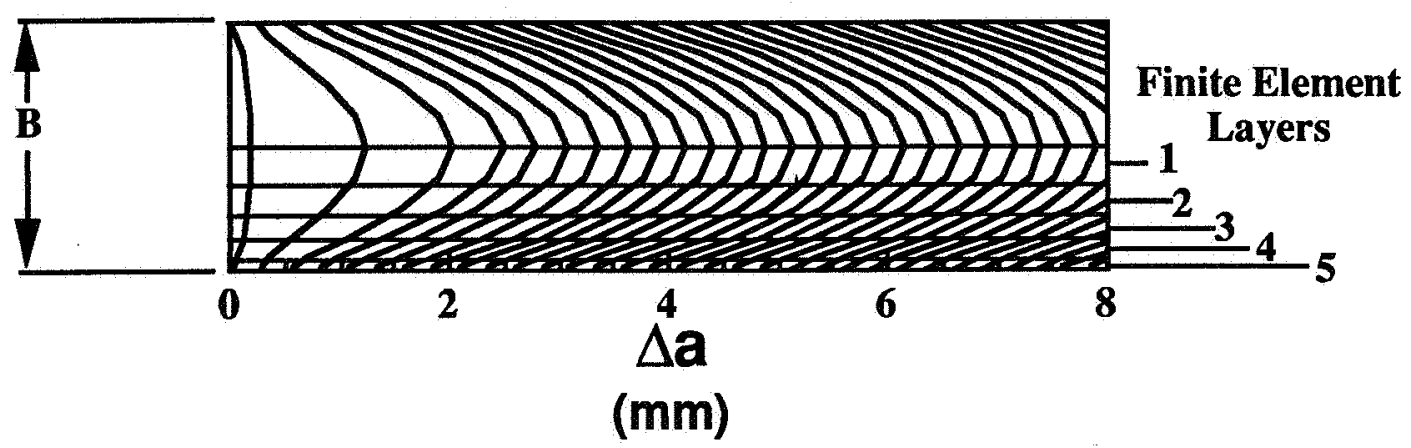

Figure 3 Crack front profiles at even increments of crack growth at the specimen surface, generated from polynomial curve fits to the measurements given in Figure 2. 


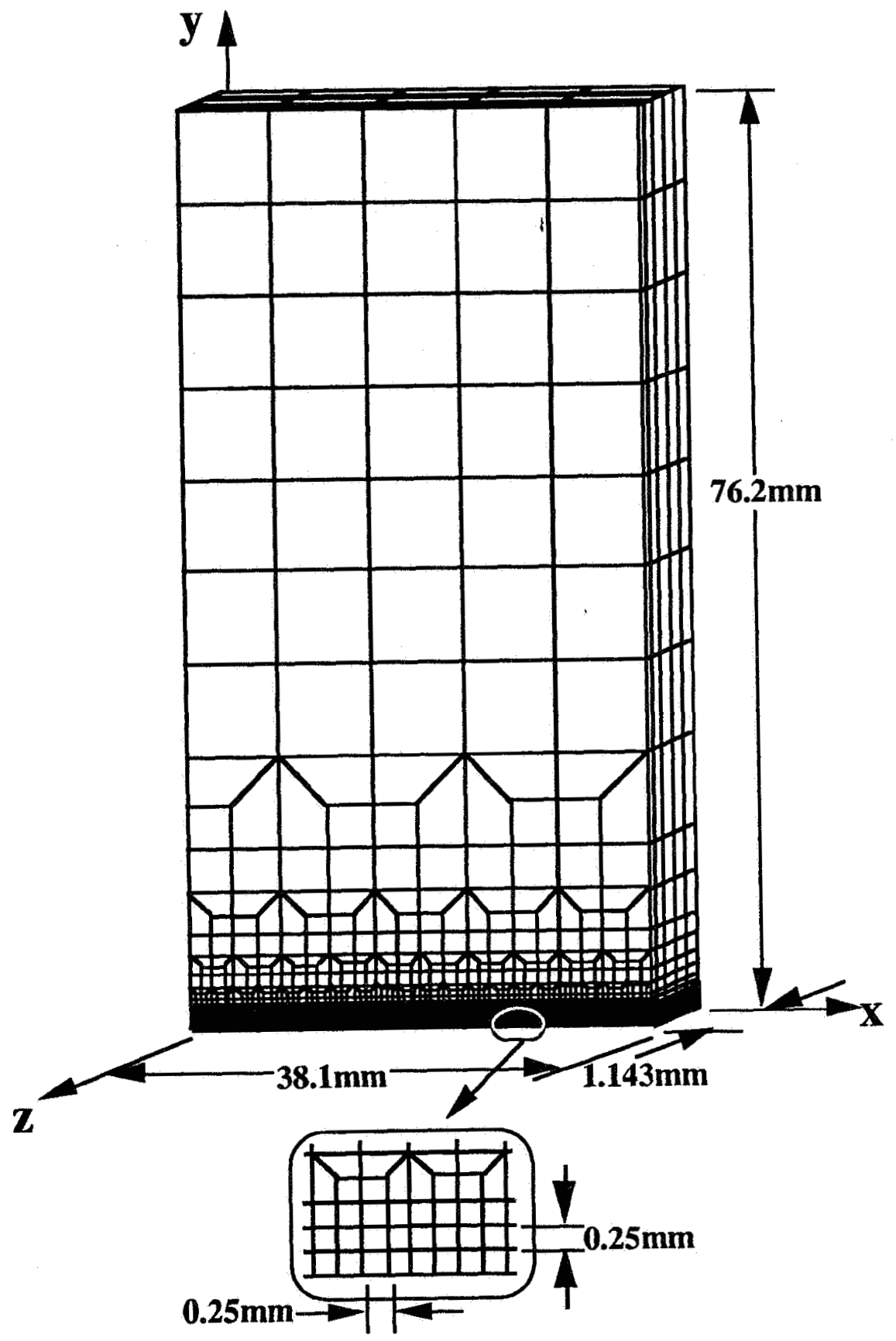

Figure 4 Finite element mesh model of $1 / 8$ th of the $M(T)$ specimen. 


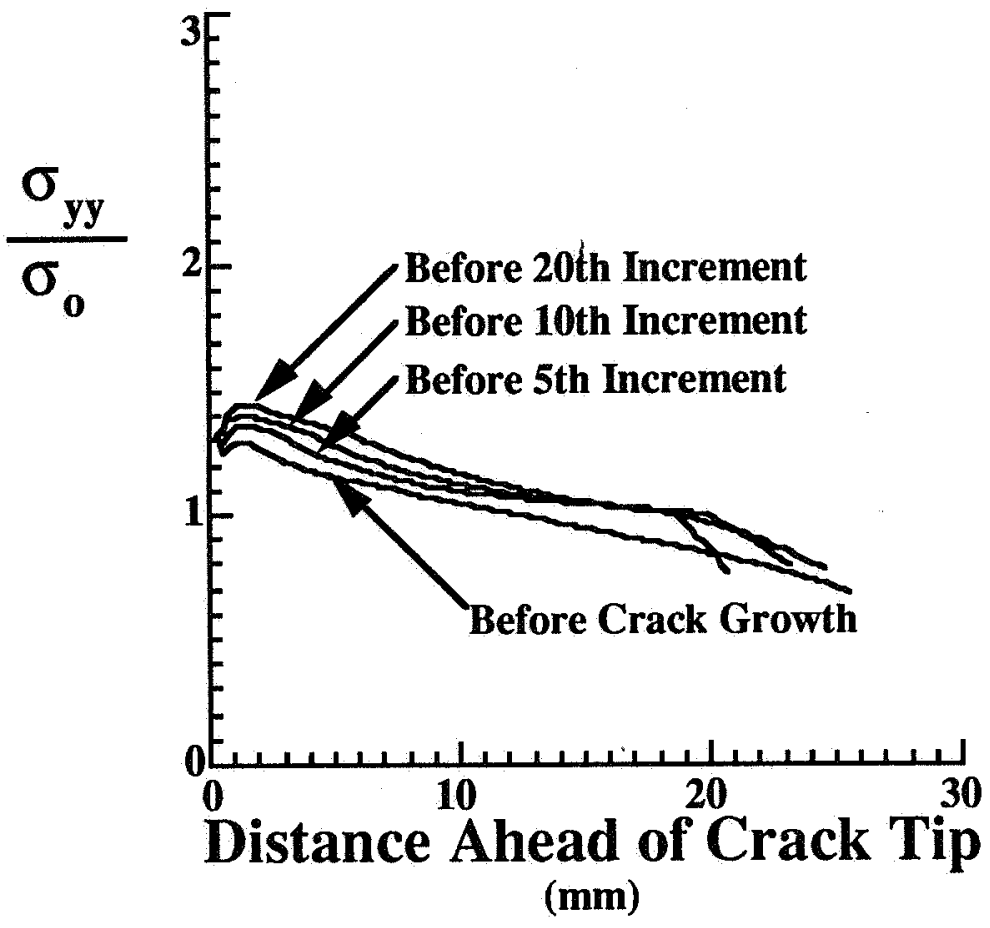

a. Surface $(\mathrm{z} / \mathrm{B}=0.5)$

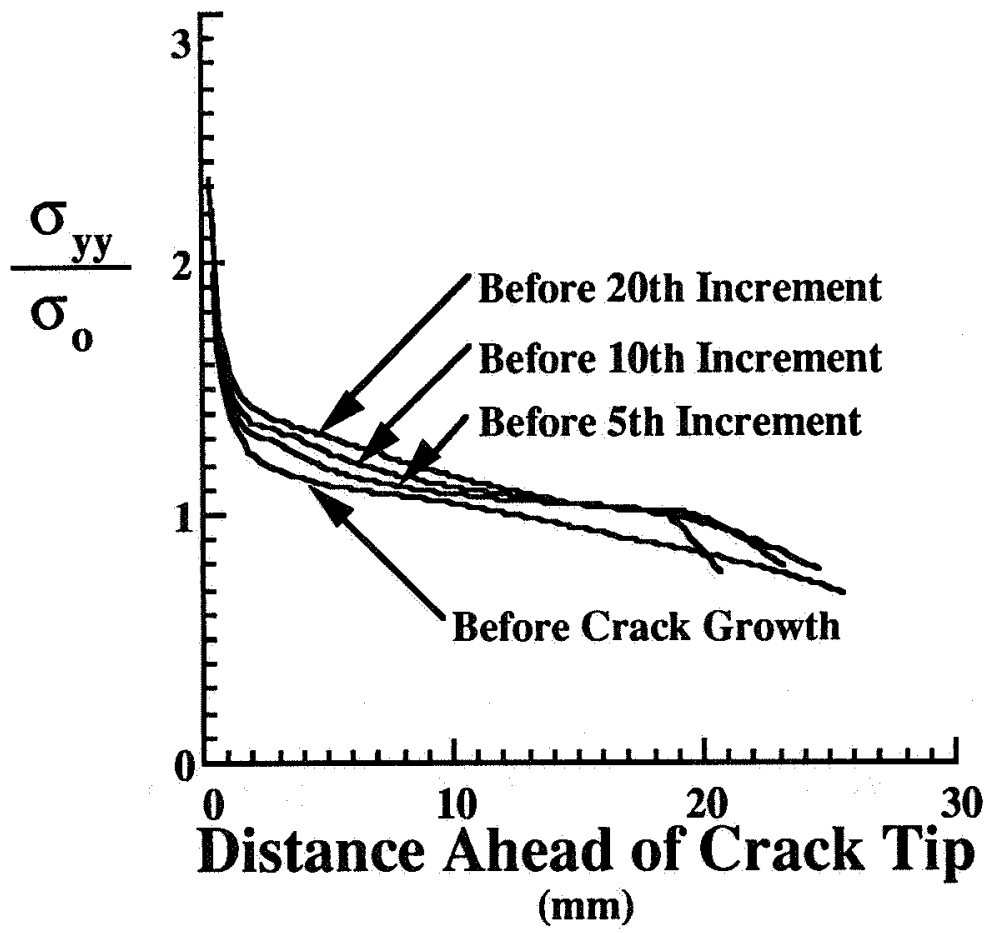

b. Mid-plane $(\mathrm{z} / \mathrm{B}=0)$

Figure $5 \quad$ Normalized $\sigma_{y y}$ stresses at the second element ahead of the crack-tip from the elastic-plastic finite element analysis of the $M(T)$ specimen with a straight crack front. 


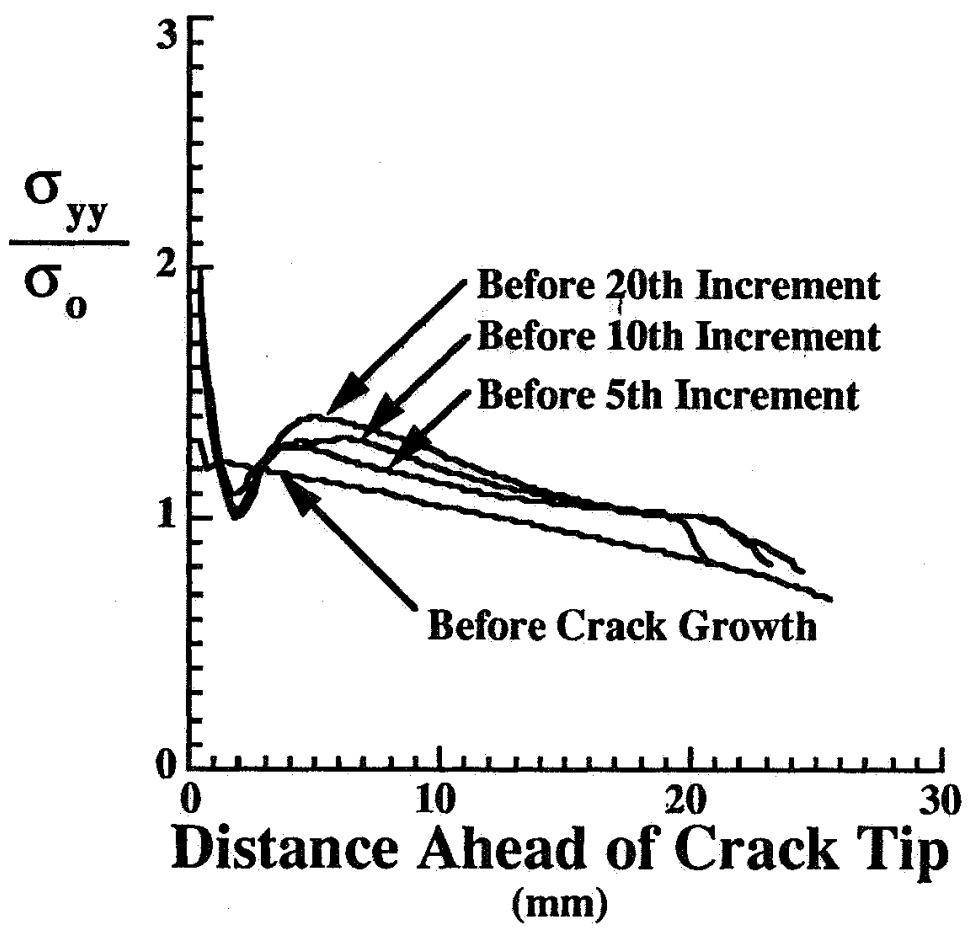

a. Surface $(\mathrm{z} / \mathrm{B}=0.5)$

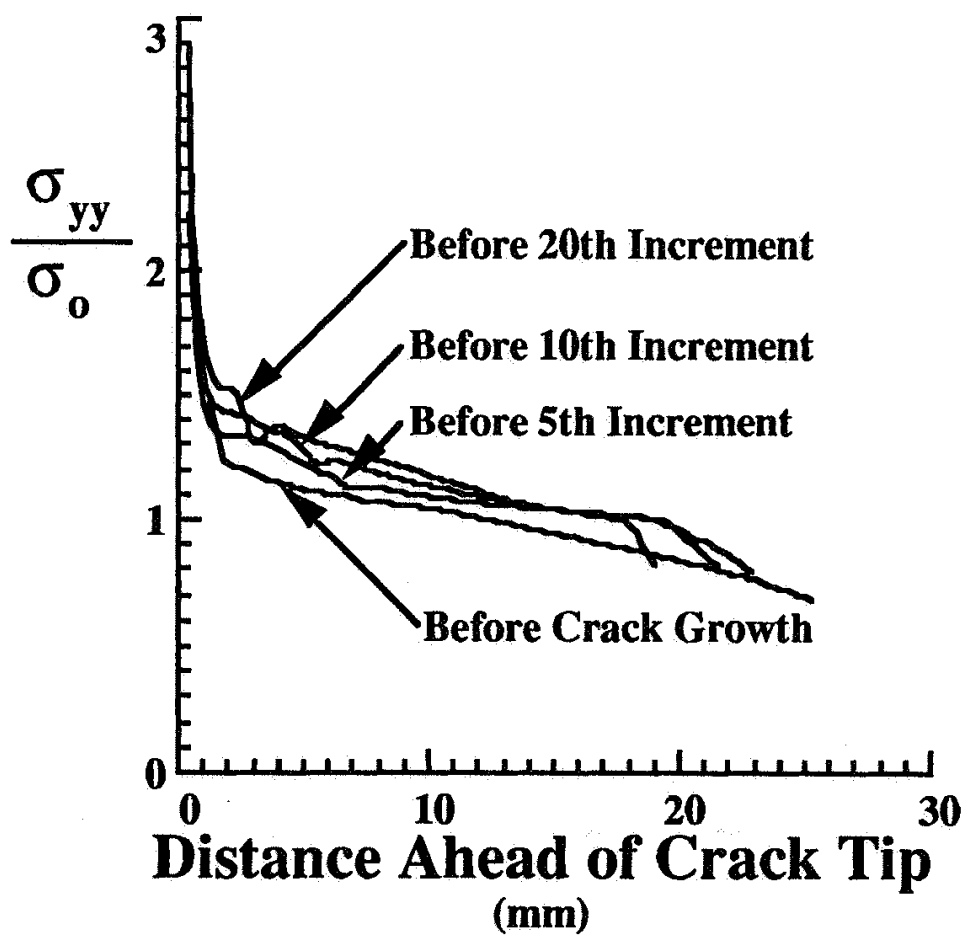

b. Mid-plane $(\mathrm{z} / \mathrm{B}=0)$

Figure 6 Normalized $\sigma_{\mathrm{yy}}$ stresses (after the first element ahead of the crack-tip) from the elastic-plastic finite element analysis of the $M(T)$ specimen with a tunneled crack front. 


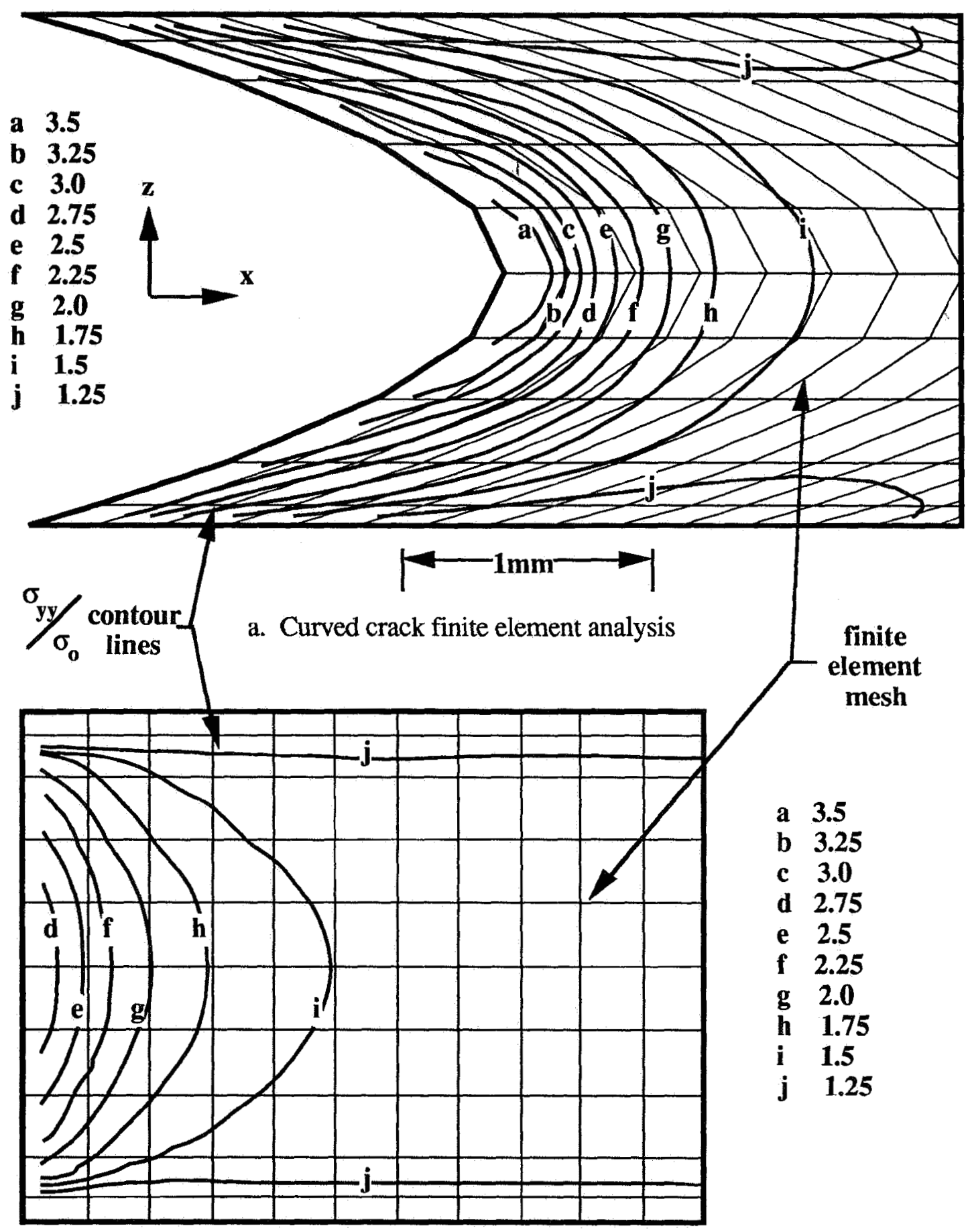

b. Straight crack finite element analysis

Figure 7 Contour plots of $\sigma_{\mathrm{yy}} / \sigma_{\mathrm{o}}$ ahead of the crack front before the 10 th increments of crack growth and the mesh pattern along the crack plane. 


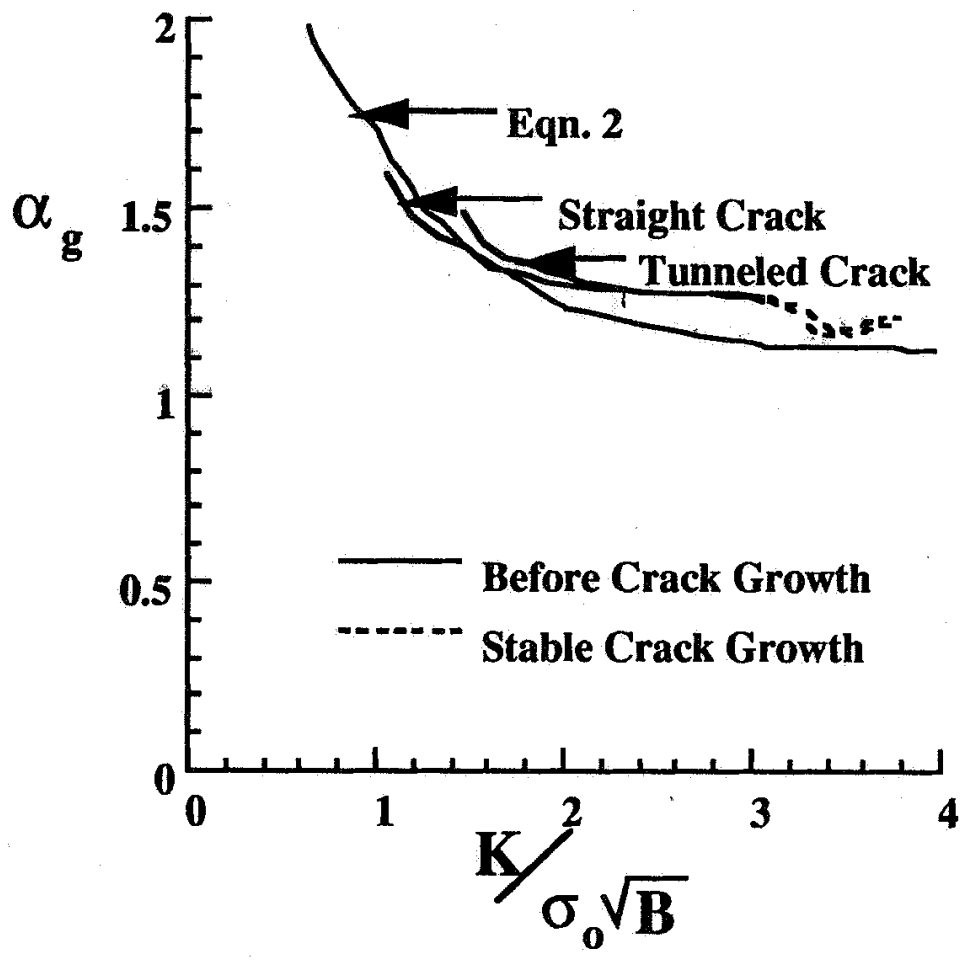

Figure 8 Global constraint factor, $\alpha_{\mathrm{g}}$, as a function of the normalized applied stressintensity factor. 


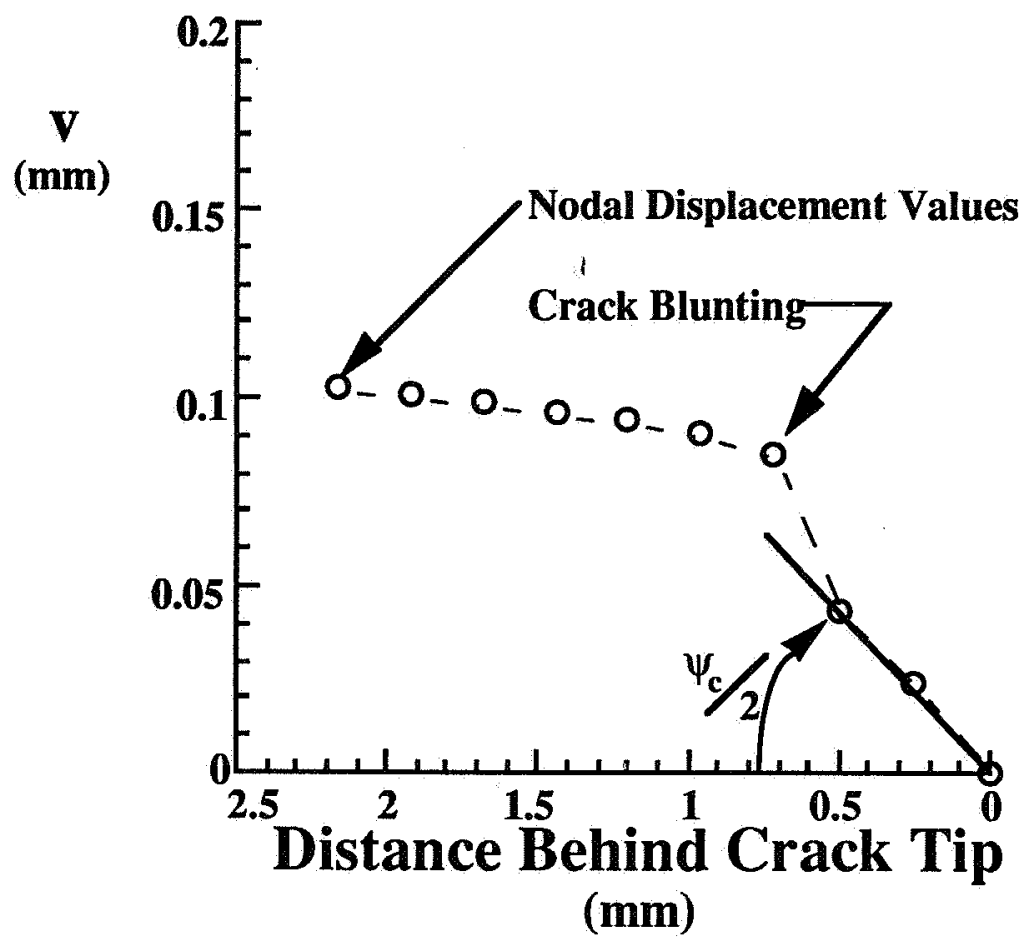

a. $0.75 \mathrm{~mm}$ of crack growth, $\psi_{\mathrm{c}}$ measured $0.5 \mathrm{~mm}$ behind crack-tip

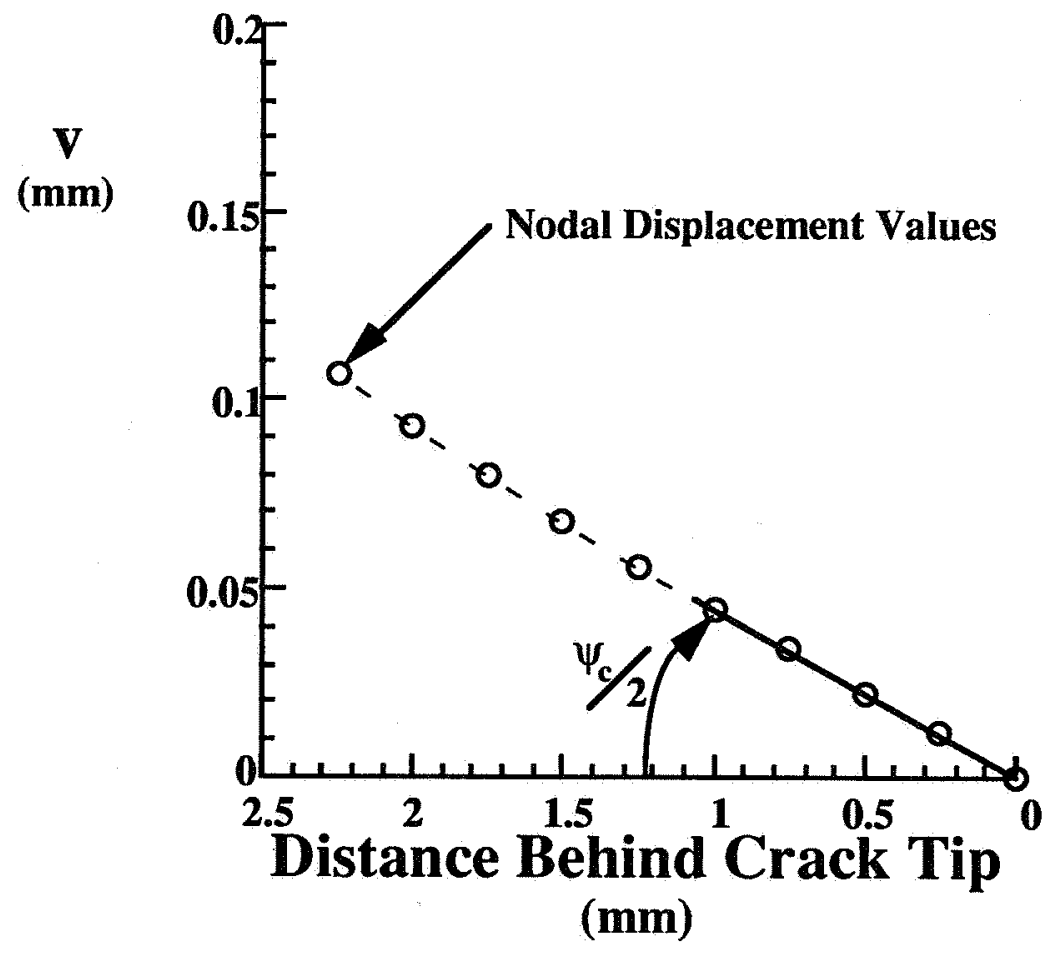

b. $3 \mathrm{~mm}$ of crack growth, $\psi_{\mathrm{c}}$ measured $1 \mathrm{~mm}$ behind crack-tip

Figure 9 Crack opening displacements at the surface for a tunneled crack front indicating the location of CTOA measurement. 


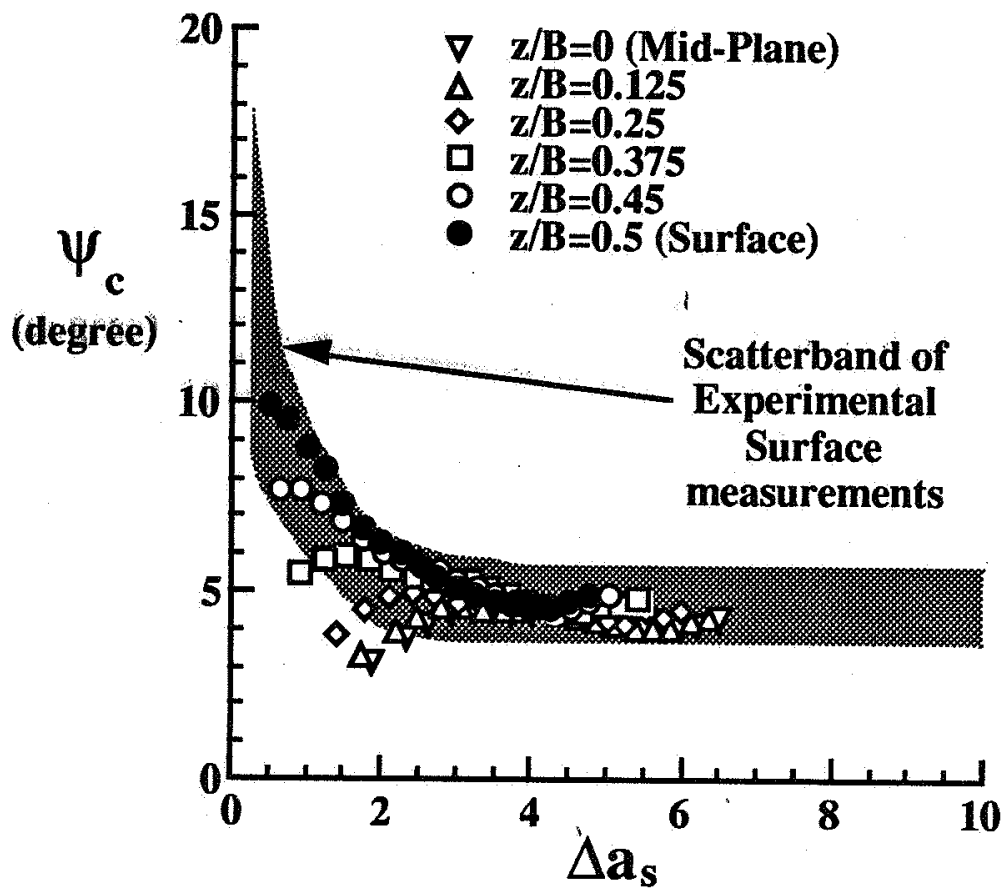

(mm)

a. finite element results for tunneled crack front

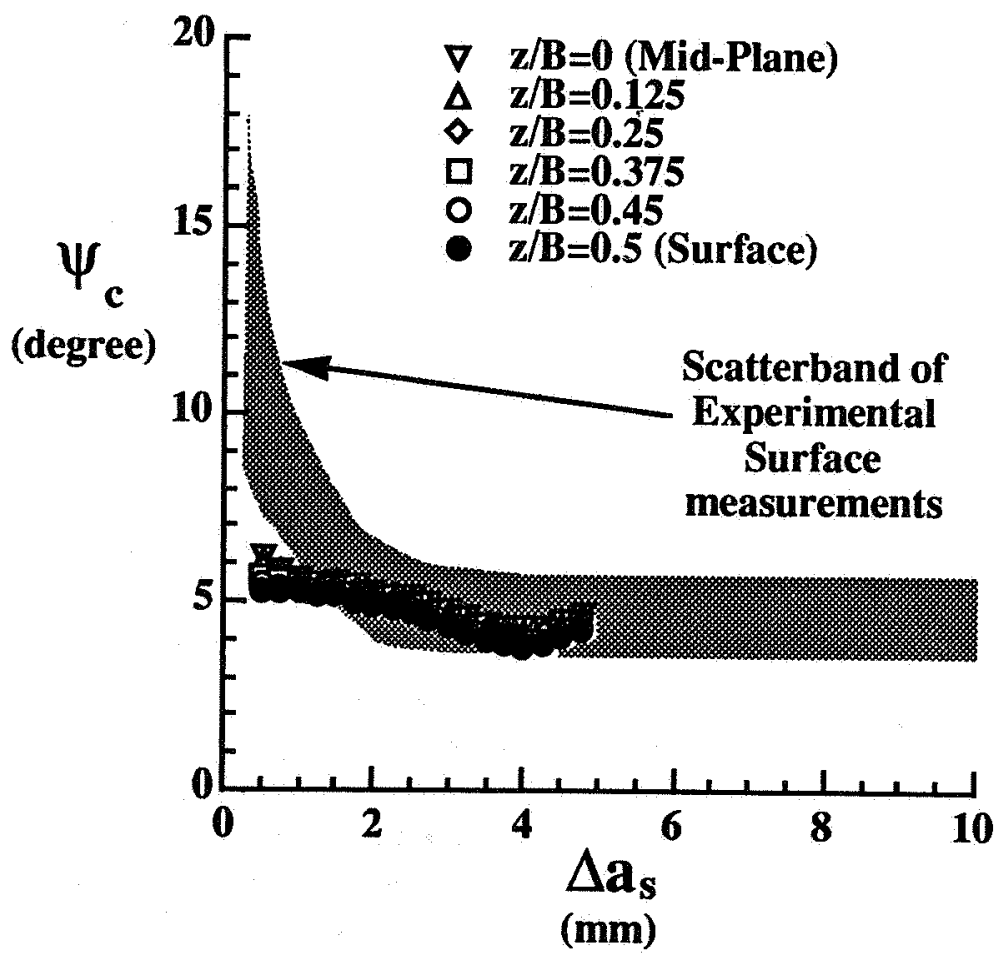

b. finite element results for straight crack front'

Figure 10 Experimental surface crack-tip opening angle measurements [17] and finite element results for a $2024-\mathrm{T} 3$ aluminum alloy in the T-L orientation. 


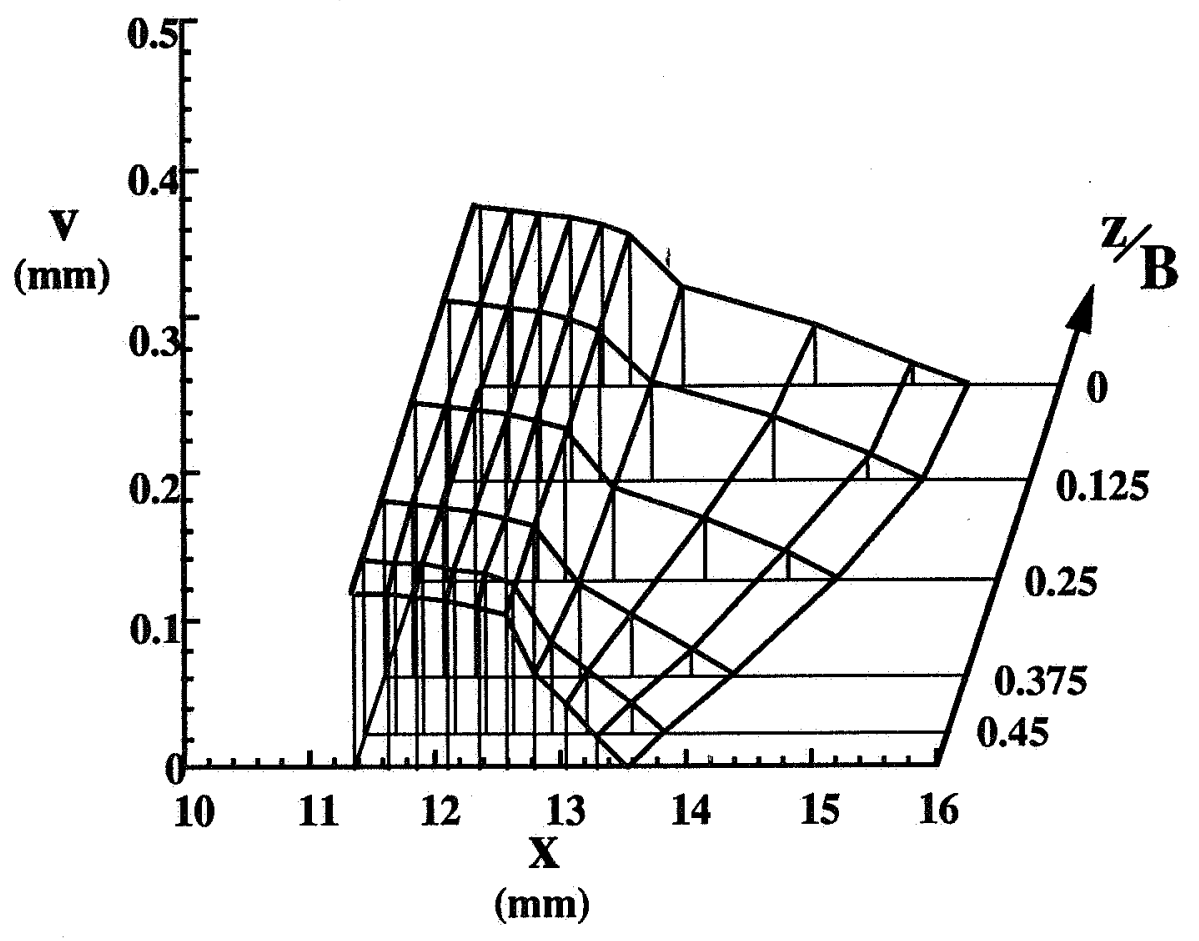

a. $\Delta \mathrm{a}_{\mathrm{s}}=0.75 \mathrm{~mm}$

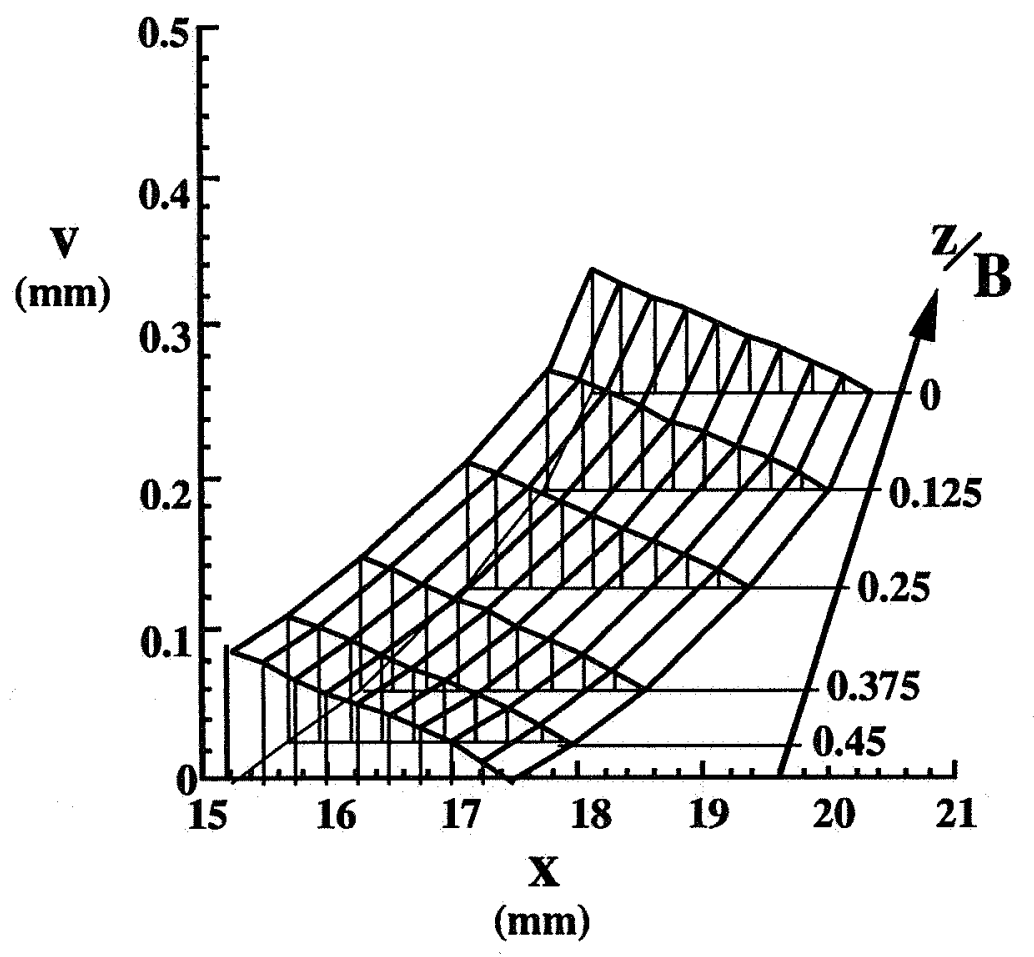

b. $\Delta \mathrm{a}_{\mathrm{s}}=4.75 \mathrm{~mm}$

Figure 11 Through-the-thickness crack opening displacement profiles for a tunneled crack front at two stages of crack growth. 


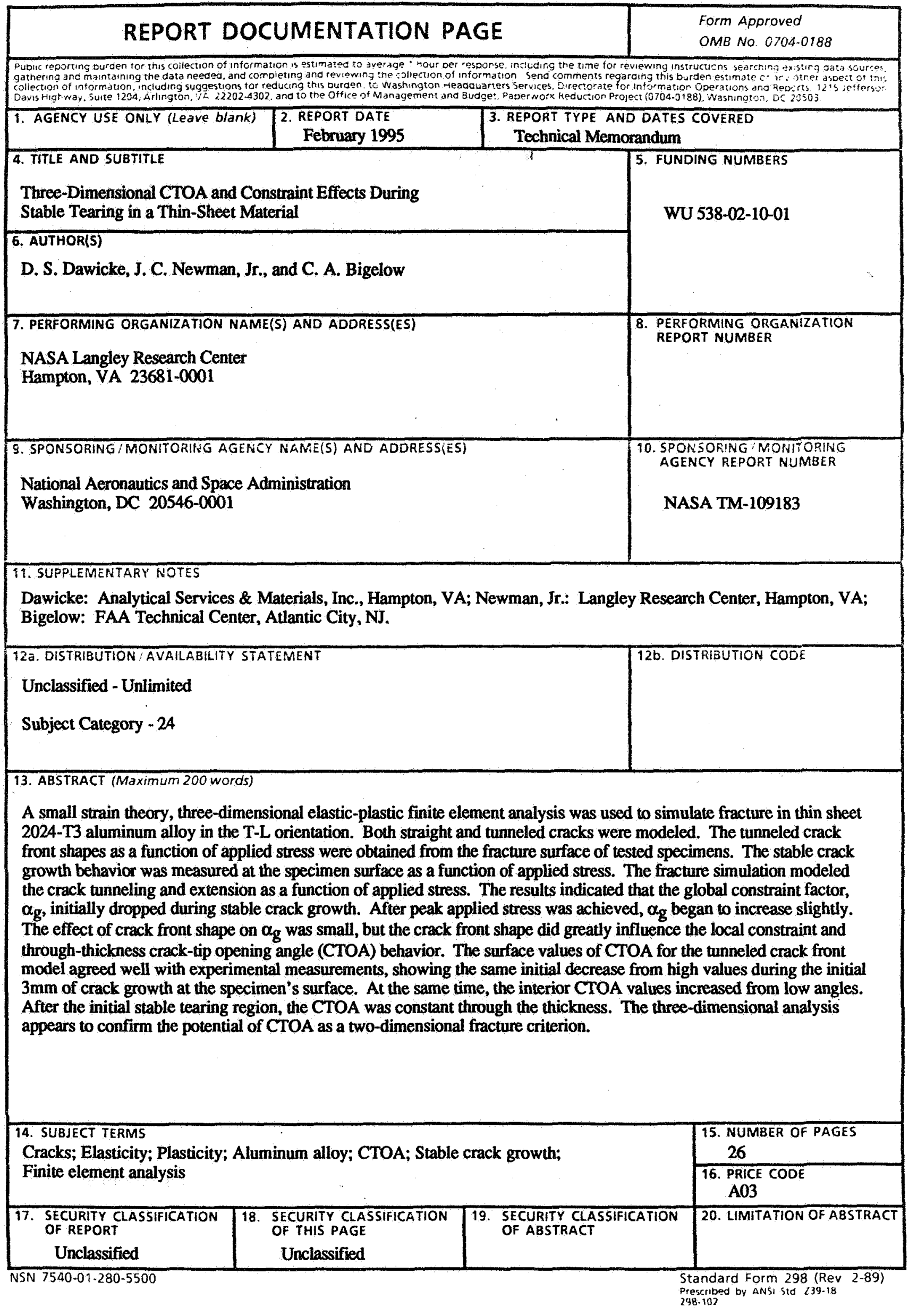

